\title{
Infantile Nystagmus Adapts to Visual Demand
}

\author{
Debbie Wiggins, ${ }^{1}$ J. Margaret Woodhouse, ${ }^{1}$ Tom H. Margrain, ${ }^{1}$ Christopher M. Harris, ${ }^{2}$ and \\ Jonathan T. Erichsen ${ }^{1}$
}

Purpose. To determine the effect of visual demand on the nystagmus waveform. Individuals with infantile nystagmus syndrome (INS) commonly report that making an effort to see can intensify their nystagmus and adversely affect vision. However, such an effect has never been confirmed experimentally.

Methods. The eye movement behavior of 11 subjects with INS were recorded at different gaze angles while the subjects viewed visual targets under two conditions: above and then at resolution threshold. Eye movements were recorded by infrared oculography and visual acuity (VA) was measured using Landolt $\mathrm{C}$ targets and a two-alternative, forced-choice (2AFC) staircase procedure. Eye movement data were analyzed at the null zone for changes in amplitude, frequency, intensity, and foveation characteristics. Waveform type was also noted under the two conditions.

RESUlTS. Data from 11 subjects revealed a significant reduction in nystagmus amplitude $(P<0.05)$, frequency $(P<0.05)$, and intensity $(P<0.01)$ when target size was at visual threshold. The percentage of time the eye spent within the low-velocity window (i.e., foveation) significantly increased when target size was at visual threshold $(P<0.05)$. Furthermore, a change in waveform type with increased visual demand was exhibited by two subjects.

Conclusions. The results indicate that increased visual demand modifies the nystagmus waveform favorably (and possibly adaptively), producing a significant reduction in nystagmus intensity and prolonged foveation. These findings contradict previous anecdotal reports that visual effort intensifies the nystagmus eye movement at the cost of visual performance. This discrepancy may be attributable to the lack of psychological stress involved in the visual task reported here. This is consistent with the suggestion that it is the visual importance of the task to the individual rather than visual demand per se which exacerbates INS. Further studies are needed to investigate quantitatively the effects of stress and psychological factors on INS waveforms. (Invest Ophthalmol Vis Sci. 2007;48: 2089-2094) DOI:10.1167/iovs.06-1108

From the ${ }^{1}$ School of Optometry and Vision Sciences, Cardiff University, Cardiff, United Kingdom; and the ${ }^{2}$ SensoriMotor Laboratory, Centre for Theoretical and Computational Neuroscience, University of Plymouth, Plymouth, United Kingdom.

Presented in part at the annual meeting of the Association for Research in Vision and Ophthalmology, Fort Lauderdale, Florida, May 2006 Society.

Supported by the Nystagmus Network (UK) and The Royal

Submitted for publication September 15, 2006; revised November 15, 2006; accepted March 8, 2007.

Disclosure: D. Wiggins, None; J.M. Woodhouse, None; T.H. Margrain, None; C.M. Harris, None; J.T. Erichsen, None

The publication costs of this article were defrayed in part by page charge payment. This article must therefore be marked "advertisement" in accordance with 18 U.S.C. $\$ 1734$ solely to indicate this fact.

Corresponding author: Jonathan T. Erichsen, School of Optometry and Vision Sciences, Cardiff University, Redwood Building, King Edward VII Avenue, Cardiff CF10 3NB, UK; erichsenjt@cf.ac.uk.
Tnfantile nystagmus (INS) is an ocular motor disorder present at birth or appearing soon thereafter. It is characterized by a conjugate and predominantly horizontal involuntary movement of the eyes, generating large retinal image velocities and subsequently degrading visual acuity (VA). ${ }^{1}$ The involuntary oscillations can be described by their amplitude, frequency, intensity, and foveation parameters. Twelve distinct waveforms have been identified for INS, all of which are a variation on either pure pendular or pure jerk oscillation. ${ }^{2}$ One important characteristic of nystagmus waveforms is the foveation time (or foveation period), which is the time during a period of oscillation when the object of regard is imaged on, or close to, the fovea and when the eye is moving slowly enough for useful vision to be achieved. ${ }^{3}$ It is thought that the developing nervous system alters the sinusoidal and jerk nystagmus so that the foveation time increases and presumably vision improves. ${ }^{4}$ However, even when the visual system is fully developed, factors such as direction of gaze and fixation distance have been shown to have profound effects on the nystagmus waveform. ${ }^{5-7}$ In addition, psychological factors including fatigue, stress, and level of attention appear to affect nystagmus oscillation; however, such effects have not been quantified. ${ }^{7}$ It is widely reported that "fixation attempt" and "effort to see" can have a deleterious effect on nystagmus oscillation due to an increase in intensity, ${ }^{1,7,8}$ but this effect has never been confirmed experimentally. Abadi and Dickinson ${ }^{7}$ demonstrated with two eye movement recordings from a single subject that nystagmus intensity increases with effort to see, although the effect was not quantified. More recently, Tkalcevic and $\mathrm{Abel}^{9}$ conducted a study to examine formally the relationship between increased visual task demand and the INS waveform. The results from their study suggested that even the maximum visual demand did not cause any change in the nystagmus waveform parameters investigated, including amplitude, frequency, intensity, and duration of foveation. However, the experimental paradigm outlined in their study may have failed to measure maximum visual demand for several reasons. These include the fact that spectacle correction was not used, thus causing some degree of blur; the visual task was performed at the primary position and not at each individual's null point, and subjects viewed the optotypes at $50 \mathrm{~cm}$ which would not allow foveal acuity to be reached in a subject with $0.0 \log$ MAR VA due to pixelation effects when using a 17-in. monitor. Nevertheless, the finding is important because it contradicts the notion that nystagmus oscillations are exacerbated by increased visual demand at the cost of visual performance. In the present study, we addressed these limitations and investigated the effects of effort to see on VA. Although it is generally agreed that the duration of the foveation period is probably the most important factor determining VA, ${ }^{2,10-12}$ other factors, including the accuracy of foveation from cycle-to-cycle and the reduction of retinal image velocities during target foveation, contribute to an increase in VA. ${ }^{13-16}$ Because the purpose of this study was to quantify the effect of visual demand on the INS waveform, the principal parameters including amplitude, frequency, intensity (amplitude $\times$ frequency), foveation duration and foveation accuracy, were considered. 
TABLE 1. Clinical Details of the Subjects

\begin{tabular}{|c|c|c|c|c|c|c|c|c|}
\hline & Age/Sex & $\begin{array}{l}\text { Clinical } \\
\text { Diagnosis }\end{array}$ & $\begin{array}{c}\text { Ocular } \\
\text { Alignment }\end{array}$ & $\mathbf{R x}$. & $\begin{array}{c}\text { VA } \\
(\log \text { MAR })\end{array}$ & $\begin{array}{l}\text { Null Angle } \\
\left({ }^{\circ}\right)\end{array}$ & $\begin{array}{c}\text { Latent } \\
\text { Component }\end{array}$ & $\begin{array}{l}\text { Waveform } \\
\text { Type }\end{array}$ \\
\hline DW & $24 / \mathrm{F}$ & Idiopathic & Ortho. & $\begin{array}{l}\text { OD: }-5.00 \text { DS } \\
\text { OS: }-5.00 \text { DS }\end{array}$ & $\begin{array}{l}\text { OD: } 0.00 \\
\text { OS: } 0.00 \\
\text { OU: } 0.00\end{array}$ & $5^{\circ}$ left & No & $\mathrm{J}_{\mathrm{EF}}$ \\
\hline GT & $38 / \mathrm{M}$ & Idiopathic & R XT & $\begin{array}{l}\text { OD: }-1.00 /-0.75 \times 35 \\
\text { OS: }-0.50 /-0.25 \times 160\end{array}$ & $\begin{array}{l}\text { OD: } 0.50 \\
\text { OS: } 0.44 \\
\text { OU: } 0.46\end{array}$ & Primary & No & $\mathrm{DJL} / \mathrm{DJR} / \mathrm{P}_{\mathrm{FS}}$ \\
\hline CA & $37 / \mathrm{M}$ & Idiopathic & L ET & $\begin{array}{l}\text { OD: }+1.50 /-2.50 \times 5 \\
\text { OS: }+2.75 /-2.75 \times 5\end{array}$ & $\begin{array}{l}\text { OD: } 0.32 \\
\text { OS: } 0.32 \\
\text { OU: } 0.32\end{array}$ & $5^{\circ}$ left & No & $\mathrm{P}_{\mathrm{FS}}$ \\
\hline TB & $25 / \mathrm{F}$ & Idiopathic & Ortho. & $\begin{array}{l}\text { OD: } \infty \\
\text { OS: } \infty\end{array}$ & $\begin{array}{l}\text { OD: } 0.40 \\
\text { OS: } 0.30 \\
\text { OU: } 0.30\end{array}$ & Primary & No & $\mathrm{J}_{\mathrm{EF}} / \mathrm{PC}$ \\
\hline DS & $33 / \mathrm{M}$ & Idiopathic & Ortho. & $\begin{array}{l}\text { OD: }-2.00 /-2.75 \times 180 \\
\text { OS: }-3.00 /-1.75 \times 170\end{array}$ & $\begin{array}{l}\text { OD: } 0.24 \\
\text { OS: } 0.18 \\
\text { OU: } 0.18\end{array}$ & $15^{\circ} \mathrm{left}$ & Yes & $\mathrm{P} / \mathrm{PC} / \mathrm{T} / \mathrm{JL}$ \\
\hline JS & $50 / \mathrm{M}$ & Idiopathic & Ortho. & $\begin{array}{l}\text { OD: }-11.50 /-2.00 \times 30 \\
\text { OS: }-10.00 /-1.50 \times 90\end{array}$ & $\begin{array}{l}\text { OD: } 0.42 \\
\text { OS: } 0.52 \\
\text { OU: } 0.42\end{array}$ & $10^{\circ}$ right & Yes & $\mathrm{JL}$ \\
\hline CT & $49 / \mathrm{F}$ & Idiopathic & R XT & $\begin{array}{l}\text { OD: balance } \\
\text { OS: }-5.75 \mathrm{DS}\end{array}$ & $\begin{array}{l}\text { OD: } \mathrm{CF} \\
\text { OS: } 0.42 \\
\text { OU: } 0.42\end{array}$ & $15^{\circ}$ right & No & DJL \\
\hline SH & $21 / \mathrm{F}$ & Idiopathic & Ortho. & $\begin{array}{l}\text { OD: }+3.00 \mathrm{DS} \\
\text { OS: }+2.25 \mathrm{DS}\end{array}$ & $\begin{array}{l}\text { OD: } 0.00^{\circ} \\
\text { OS: } 0.32 \\
\text { OU: } 0.00^{\circ}\end{array}$ & Primary & Yes & $\mathrm{JL}_{\mathrm{EF}}$ \\
\hline $\mathrm{RB}$ & $20 / \mathrm{F}$ & Idiopathic & Ortho. & $\begin{array}{c}\text { OD: }-4.25-/ 0.75 \times 125 \\
\text { OS: }-3.50 /-1.50 \times 55\end{array}$ & $\begin{array}{l}\text { OD: } 0.22 \\
\text { OS: } 0.32 \\
\text { OU: } 0.12\end{array}$ & $10^{\circ} \mathrm{left}$ & No & $\mathrm{J}_{\mathrm{EF}}$ \\
\hline PW & $37 / \mathrm{M}$ & Idiopathic & Ortho. & $\begin{array}{l}\text { OD: }+2.25 /-1.25 \times 170 \\
\text { OS: }+0.50 /-0.75 \times 5\end{array}$ & $\begin{array}{l}\text { OD: } 0.30 \\
\text { OS: } 0.10 \\
\text { OU: } 0.10^{\circ}\end{array}$ & $10^{\circ}$ right & No & $\mathrm{JR}_{\mathrm{EF}}$ \\
\hline $\mathrm{BE}$ & $62 / M$ & Ocular albinism & Alt. XT & $\begin{array}{l}\text { OD: }+2.25 /-6.75 \times 180 \\
\text { OS: }+1.25 /-6.50 \times 5\end{array}$ & $\begin{array}{l}\text { OD: } 0.50 \\
\text { OS: } 0.50 \\
\text { OU: } 0.50\end{array}$ & $5^{\circ}$ right & No & $\mathrm{JL}$ \\
\hline
\end{tabular}

Ortho, orthotropia; XT, exotropia; ET, esotropia; Alt., alternating; R, right; L, left; CF, count fingers; $\mathrm{J}_{\mathrm{FF}}$, jerk with extended foveation; DJL, dual jerk left; DJR, dual jerk right; $\mathrm{P}_{\mathrm{FS}}$, pendular with foveating saccades; PC, pseudo cycloid; $\mathrm{P}$, pure pendular; $\mathrm{T}$, triangular; JL, jerk left; JL $\mathrm{L}_{\mathrm{EF}}$, jerk left with extended foveation; $\mathrm{JR}_{\mathrm{EF}}$, jerk right with extended foveation.

\section{MethodS}

\section{Subjects}

Eye movements were examined in 11 subjects with INS. The subjects had either idiopathic nystagmus or ocular albinism, as determined by prior clinical examination. Ten subjects were classified as having idiopathic nystagmus (age range: $20-50$ years, mean, 33.4, VA range: $0.00-0.46 \log \mathrm{MAR}$, mean $\mathrm{VA}=0.22$ ) and one as having ocular albinism (age 62 years, $\mathrm{VA}=0.50 \log \mathrm{MAR}$ ). The presence of periodic alternating nystagmus (PAN) was examined in eye movement recordings obtained before data collection for this study. ${ }^{17}$ None of the 11 subjects who took part in this study exhibited PAN. Clinical and ocular motor findings in the participants are summarized in Table 1. All participants were naive with respect to the experimental paradigm. Recruitment and trials were conducted in accordance with the Declaration of Helsinki. Written informed consent was obtained after explanation of the nature and possible consequences of the study. Approval for the ethics of the study was granted by the Bro Taf local research ethics committee.

\section{Eye Movement Recordings}

Eye movements were recorded (IRIS system; Skalar Medical BV, Delft, The Netherlands). This system is based on the principle of reflection of infrared light by the sharp boundary between the iris and sclera. The IRIS system is capable of detecting eye movements with a high spatial resolution $\left(0.1^{\circ}\right)$ and temporal resolution
$(100 \mathrm{~Hz})$. The output of the device is linear within $3 \%$ up to $\pm 25^{\circ}$ horizontal eccentricity. ${ }^{18}$

\section{Experimental Setup}

The experimental setup consisted of a front surface mirror $(750 \times 350$ $\mathrm{mm}$ ) attached to a computer-controlled DC motor. The motor was capable of driving the mirror through a range of angles with an accuracy of $1^{\circ}$. The mirror-motor arrangement was positioned on a table so that the center of rotation of the mirror was $20 \mathrm{~cm}$ from the patient. A high-quality monitor positioned adjacent to the rotating mirror displayed the stimulus. A second mirror at the opposite end of the laboratory reflected an image of the stimulus generated by the computer monitor so that it was seen in the mirror positioned directly in front of the patient. This mirror arrangement allowed a working distance of $7 \mathrm{~m}$ enabling foveal acuity to be measured at a range of gaze angles. The angle of the rotating mirror determined the orbital eye position that the subject had to adopt to view the stimulus. Following the laws of incidence and reflection, the mirror had to turn through half the amount of the required gaze angle.

Eye movements were calibrated by driving the mirror in a sawtooth pattern over $\pm 10^{\circ}$ for 40 seconds at $0.25 \mathrm{~Hz}$, while a black spot subtending $0.2^{\circ}$ was displayed on the monitor. Subjects were instructed to follow the target as accurately as possible. Chin, head, and cheek rests were used to stabilize head position during recording. Subsequently, by plotting eye position against target position, we used the eye position data to calibrate the output of the IRIS system. 


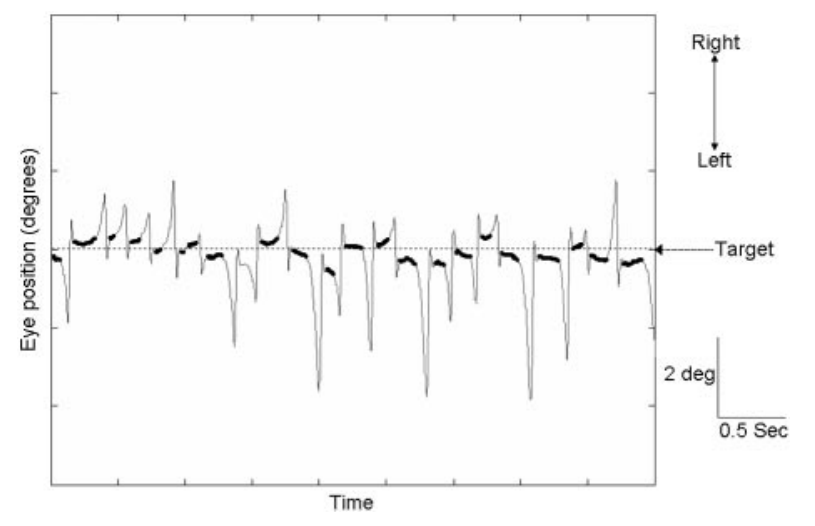

FigURE 1. Eye position recording (OS) for subject DW viewing using the null position. A jerk waveform with extended foveation $\left(J_{\mathrm{EF}}\right)$ is displayed. Foveation periods (bold) were identified by using algorithms written in commercial software (MatLab; The MathWorks, Natick, MA). A target trace is included to show the position of the stationary target. In this and all other waveform figures, up denotes rightward eye movements and down represents leftward eye movements.

\section{Protocol}

This investigation was part of a larger study involving multiple gaze positions. The visual task for this research was conducted at the subject's null zone, where maximum visual effort and best acuity would normally occur. The subject's task was to locate the gap in a single Landolt $\mathrm{C}$ presented in the center of a 17 -in. monitor from a choice of two orientations (gap left or gap right; i.e., 2AFC). The subjects relayed their choices by using a push-button array. Viewing time for each presentation was unrestricted, although each subject was instructed to respond as quickly and accurately as possible. All subjects wore their full spectacle correction. The starting target size was chosen to be $0.4 \log$ units above the subject's best clinical VA (logMAR letter chart). The presentation of subsequent Landolt $\mathrm{C}$ targets followed a $\log$ staircase procedure working on a three-up, one-down principle. ${ }^{19}$ The staircase was terminated once threshold had been detected (mean of eight reversals). Seven subjects performed the test binocularly; four subjects had manifest strabismus and therefore completed the task monocularly. No auditory or other feedback was provided throughout the task.

Six seconds of eye movement data, recorded when VA was at threshold, were used to characterize eye movement behavior at maximum visual effort where visual demand was highest. Six seconds of eye movement data recorded when target presentation was 1 step size smaller than the largest (initial) target size (i.e., well above threshold) were used to characterize eye movement behavior at minimum visual effort. To minimize any possible learning and stress effects influencing the data, three practice trials were conducted before data collection. Thus, the overall task demand was minimized.

Eye movement data were analyzed for differences in amplitude, frequency, and intensity during the two conditions: minimum and maximum visual demand. Information on these parameters was extracted from the eye position and velocity recordings using manual analysis conducted by two independent experienced observers. Differences in foveation duration were also examined. Foveation periods were defined as when the eye velocity was $<4^{\circ} / \mathrm{sec}$ and eye position $\pm 2^{\circ}$ from the point of fixation from cycle to cycle. ${ }^{12,20}$ Foveation periods were identified using algorithms written in commercial software (MatLab; ver. 7.1; The MathWorks, Inc., Natick, MA; Fig. 1). Data were also inspected for differences in waveform type during the two conditions.

\section{Results}

The results showing the effects of increased visual demand on the INS parameters are summarized in Table 2.

Analyses of combined data from the 11 subjects revealed significant differences in nystagmus amplitude, frequency, and intensity when assessed at minimum and maximum visual demand by using paired $t$-tests. Nystagmus amplitude decreased when targets were at threshold level: average reduction $27 \%$ (95\% confidence interval [CI], 2\%-46\%; $P<0.05$ ). Nystagmus frequency also declined when subjects were viewing at threshold level: average reduction 14\% (95\% CI, 1\%-26\%; $P<0.05)$. Finally, nystagmus intensity was, on average, reduced by $37 \%$ (95\% CI, 15\%-54\%; $P<0.01$; Fig. 2).

Analysis of foveation data from the 11 subjects reveals a significant increase in the time the eye spent within the foveation window during periods of maximum visual demand (Table 3). At the null zone, foveation duration increased when targets were at threshold level: average increase 6.56\% (95\% CI, $0.32 \%-12.79 \% ; P<0.05$; paired $t$-test). Figure 3 shows the change in foveation characteristics in subject DS during minimum and maximum visual demand. The standard deviation of eye position (SDp) during foveations (calculated from the SD of the mean position of each foveation period identified within a sample block) did not change during increased visual demand.

Two of the 11 subjects displayed a change in predominant waveform type when viewing targets at visual threshold. Fig-

TABLE 2. Change in Nystagmus Waveform Parameters with Minimum and Maximum Visual Demand

\begin{tabular}{|c|c|c|c|c|c|c|}
\hline \multirow[b]{2}{*}{ Subject } & \multicolumn{2}{|c|}{ Amplitude $\left(^{\circ}\right)$} & \multicolumn{2}{|c|}{ Frequency (Hz) } & \multicolumn{2}{|c|}{ Intensity (Amp. $\times$ Freq.) } \\
\hline & $\begin{array}{l}\text { Min. Visual } \\
\text { Demand }\end{array}$ & $\begin{array}{l}\text { Max. Visual } \\
\text { Demand }\end{array}$ & $\begin{array}{l}\text { Min. Visual } \\
\text { Demand }\end{array}$ & $\begin{array}{l}\text { Max. Visual } \\
\text { Demand }\end{array}$ & $\begin{array}{l}\text { Min. Visual } \\
\text { Demand }\end{array}$ & $\begin{array}{l}\text { Max. Visual } \\
\text { Demand }\end{array}$ \\
\hline DW & 1.62 & 1.99 & 4.56 & 3.57 & 7.38 & 7.10 \\
\hline GT & 5.72 & 1.94 & 4.29 & 4.62 & 24.54 & 8.96 \\
\hline $\mathrm{CA}$ & 1.39 & 1.06 & 3.67 & 3.50 & 5.10 & 3.71 \\
\hline TB & 1.71 & 2.25 & 7.04 & 6.16 & 12.02 & 13.83 \\
\hline DS & 1.75 & 0.64 & 5.33 & 6.17 & 9.33 & 3.95 \\
\hline JS & 5.00 & 5.06 & 4.98 & 4.48 & 24.90 & 22.62 \\
\hline CT & 0.93 & 0.60 & 2.17 & 1.67 & 2.02 & 1.00 \\
\hline $\mathrm{SH}$ & 1.26 & 0.78 & 1.50 & 1.16 & 1.89 & 0.91 \\
\hline $\mathrm{RB}$ & 2.24 & 1.80 & 4.00 & 3.83 & 8.97 & 6.89 \\
\hline PW & 1.60 & 1.70 & 4.83 & 4.33 & 7.73 & 7.36 \\
\hline $\mathrm{BE}$ & 2.15 & 1.27 & 3.33 & 1.67 & 7.17 & 2.12 \\
\hline Mean $\pm \mathrm{SE}$ & $2.31 \pm 0.49$ & $1.74 \pm 0.39$ & $4.15 \pm 0.48$ & $3.74 \pm 0.54$ & $10.10 \pm 2.47$ & $7.13 \pm 2.03$ \\
\hline
\end{tabular}

Log transformation was applied to the data to allow for parametric analysis. 

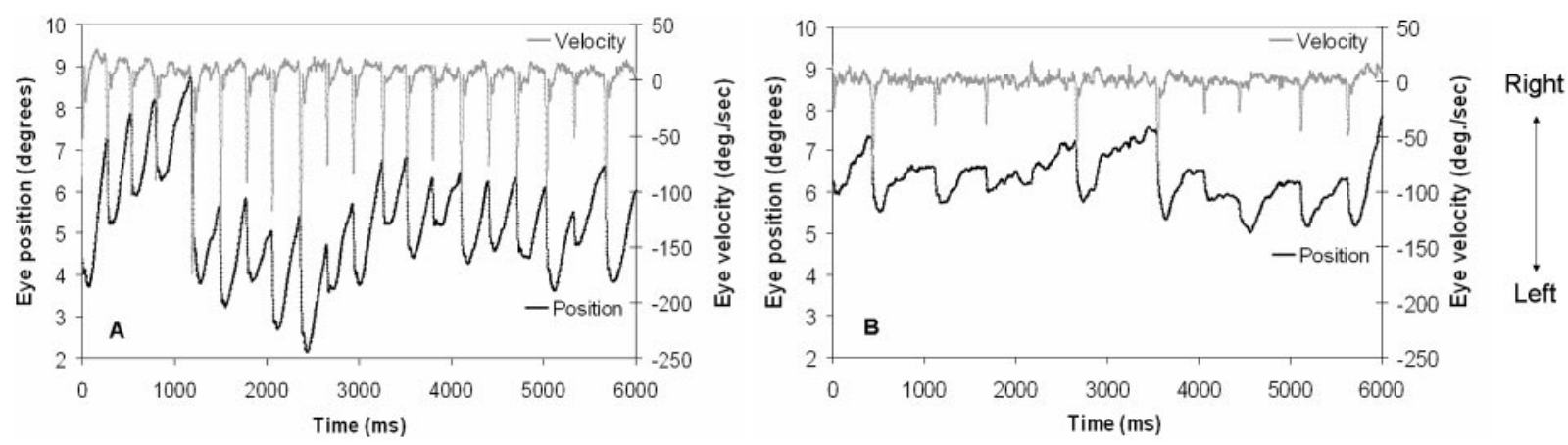

Figure 2. Eye position and velocity recording (OS) for subject BE during minimum (A) and maximum (B) visual demand. Both show a left-beating jerk waveform (JL). During maximum visual demand $(\mathbf{B})$, a reduced intensity oscillation is displayed.

ures 3 and 4 show the eye movement position recordings for subjects DS and GT during minimum and maximum visual demand.

\section{Discussion}

The results indicate that increased visual demand modifies the nystagmus waveform favorably, producing a significant reduction in nystagmus intensity and prolonged foveation. This contradicts previous reports that effort to see intensifies the nystagmus eye movement at the cost of visual performance. $1,7,8,10,21$ The reason for this discrepancy may be the lack of psychological stress ${ }^{22}$ involved in the visual task (i.e., low task demand) reported herein, as subjects gained no reward by performing well. This conclusion is consistent with the suggestion by Tkalcevic and $\mathrm{Abel}^{9}$ that the visual importance of the task to the individual rather than visual demand per se exacerbates INS. Although there are many similarities between our study and theirs, different conclusions were drawn. The former study found amplitude, frequency, and intensity to be unaffected by the level of visual demand. We speculate that this finding is due to the different experimental paradigms adopted (i.e., the former study did not allow maximum visual effort to be achieved). Nevertheless, both studies agree that increased visual demand per se does not increase nystagmus eye movements.

These data strongly suggest that we should consider two modulatory factors in INS: visual demand/attention of the subject and any stress/arousal induced by the task. In many natural tasks, resolving small visual details is important to the individ- ual and hence these two factors often coincide. However, in our experiment there was no explicit reward for using maximum visual effort, and practice trials may have further reduced stress. Thus, we are likely to have largely removed any task demand and its associated stress or arousal.

The mechanism by which waveform changes with visual demand is unknown. Harris ${ }^{23}$ proposed that INS could be due to a mismatch of an internal (efference copy) gain within the smooth pursuit subsystem, and Jacobs and Dell'Osso ${ }^{24}$ have hypothesized that INS is caused by a developmental or innate failure to calibrate this internal gain. However, if increased visual demand leads to a gain increase, one would expect nystagmus intensity to increase, rather than decrease as we observed. It seems counterintuitive that increased visual demand should lead to a reduction in gain. In contrast, increased visual demand could lead to an increase in visual feedback gain that could dampen instability by counteracting high internal gains. Beneficial effects on INS waveforms have also been reported after afferent stimulation ${ }^{16}$ and extraocular tenotomy. ${ }^{25,26}$ It has been hypothesized that palisade endings identified at the myotendinous junction of nontwitch muscle fibers in extraocular muscles may provide a proprioceptive pathway from eye muscles to the brain. ${ }^{27,28}$ Such effects could therefore arise from a reduction in an internal (i.e., proprioceptive rather than efference copy) loop directly. It is interesting to note that the nucleus of the optic tract (NOT) receives proprioceptive and retinal slip inputs, as well as information from the pregeniculate nucleus relating to visual attention. ${ }^{29,30}$ In turn, the NOT projects to the gaze-holding centers and has been shown to mediate adaptive gain of horizontal nystagmus. ${ }^{31}$

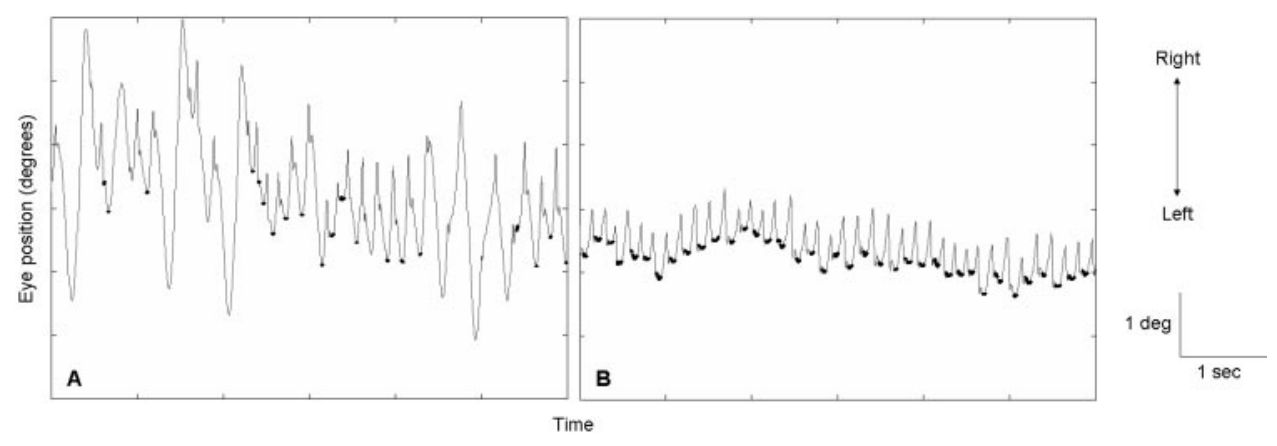

FIGURE 3. Eye position recording (OD) for subject DS during minimum (A) and maximum (B) visual demand. Foveation periods (bold) show a change in foveation characteristics. During minimum visual demand (A), the eye spent $6.28 \%$ of the time within the foveation window, increasing to $30.67 \%$ with maximum visual demand (B). Three different waveforms (pendular [P], pseudocycloid [PC], and triangular [T]) were recorded for DS during minimum visual demand (A); during maximum visual demand, DS displayed a left-beating jerk waveform (JL) (B). 


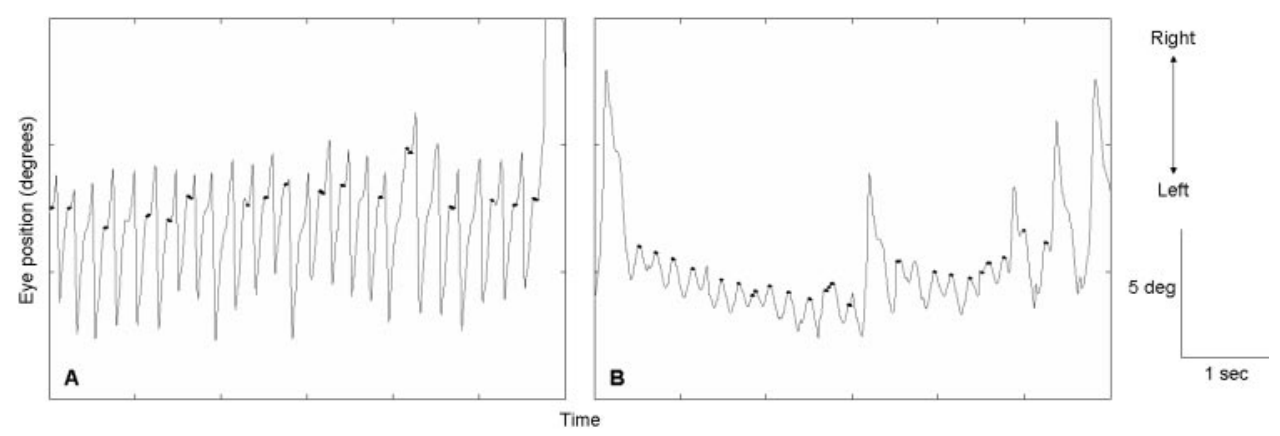

FIGURE 4. Eye position recording (OS) for subject GT. During minimum visual demand, GT displayed a dual jerk left (DJL) waveform (A); during maximum visual demand, a pendular with foveating saccades $\left(\mathrm{P}_{\mathrm{FS}}\right)$ waveform was recorded with beats of dual jerk right (DJR) interspersed (B). Foveation periods are shown in bold. During minimum visual demand (A), the eye spent $8.08 \%$ of the time within the foveation window, increasing to $11.67 \%$ with maximum visual demand (B).

Whatever the anatomic substrate underlying the observed change in the nystagmus waveform in response to increased visual demand, our finding is also consistent with a recent adaptive/developmental model proposed by Harris and Berry. ${ }^{32,33}$ Attention to small visual details requires sensitivity to high spatial frequencies, which would be enhanced with slower and longer foveation periods, whereas low spatial frequency sensitivity would be enhanced by higher retinal image slip. Harris and Berry have proposed that early deprivation of high spatial frequency information may result in a developmental shift toward generating desirable image motion via nystagmus. This emerges in early infancy, when plasticity is high (critical period), and is locked in permanently as plasticity wanes. Our findings clearly demonstrate plasticity in some adults, where foveation periods can be extended to some degree, but where there is insufficient adaptive range to eliminate the nystagmus altogether. Of note, the two subjects who did not exhibit an increase in foveation duration with increased visual demand had repeatable waveforms (of the same type) with well-developed foveation and good VA, and therefore may gain very little benefit from further adaptations. The SDp during foveation was unaffected by increased visual task demand. The position of a foveation period depends on the end point of the preceding quick phase. It is possible that end point SD is not very controllable, although this needs further investigation.

The present findings have additional implications for studies that have examined the relationship between VA and nys- tagmus, since most researchers have recorded eye movements only after acuity has been measured (i.e., when the effort to see is minimal). This study strongly suggests that quantifying the relationship between nystagmus eye movements and VA is only possible if the two are measured simultaneously.

Having found the effects of visual demand, it would now be interesting to measure the effects of task demand. Based on anecdote and many personal observations, we expect the waveform to change with stress, presumably mediated by the reticular formation. However, we can now surmise that the effects of stress and visual demand need to be dissociated. Therefore, we are currently investigating how stressors affect INS independent of any change in visual demand.

Finally, this study demonstrates that language must be chosen carefully when describing a subject's response to task demand. The terms "effort to see" and "fixation attempt" can be confusing as they combine two distinct constructs: attempting to resolve higher spatial frequencies and the arousal and stress induced by tasks, such as (but not limited to) resolving fine details. Clearly, these two demands evoke entirely different responses in the infantile nystagmat and should be considered independently.

\section{Acknowledgments}

The authors thank all the participants who volunteered to take part in the study, Fergal Ennis for contributions to the study design and loan of equipment, Nathan Bromham for valuable assistance in computer programming, and Michael Johnson for help with statistical analysis.

TABLE 3. Change in Foveation Characteristics with Minimum and Maximum Visual Demand

\begin{tabular}{|c|c|c|c|c|c|}
\hline \multirow[b]{2}{*}{ Subject } & \multicolumn{3}{|c|}{$\begin{array}{l}\% \text { of Time in Low-Velocity Window } \\
\qquad(<4 \% \text { sec })\end{array}$} & \multicolumn{2}{|c|}{ SDp } \\
\hline & $\begin{array}{l}\text { Min. Visual } \\
\text { Demand }\end{array}$ & $\begin{array}{l}\text { Max. Visual } \\
\text { Demand }\end{array}$ & $\begin{array}{l}\% \text { Change for } \\
\text { Each Subject }\end{array}$ & $\begin{array}{l}\text { Min. Visual } \\
\text { Demand }\end{array}$ & $\begin{array}{l}\text { Max. Visual } \\
\text { Demand }\end{array}$ \\
\hline DW & 40.62 & 37.17 & -8.49 & 0.35 & 0.26 \\
\hline GT & 8.08 & 11.67 & +44.43 & 0.44 & 0.35 \\
\hline $\mathrm{CA}$ & 11.77 & 23.73 & +101.61 & 0.46 & 0.25 \\
\hline TB & 24.13 & 24.15 & +0.08 & 0.63 & 0.83 \\
\hline DS & 6.28 & 30.67 & +388.38 & 0.77 & 0.25 \\
\hline JS & 0.75 & 2.06 & +174.67 & 0.79 & 1.02 \\
\hline CT & 54.18 & 74.30 & +37.14 & 0.44 & 0.35 \\
\hline SH & 77.25 & 88.75 & +14.89 & 0.26 & 0.34 \\
\hline $\mathrm{RB}$ & 35.37 & 32.18 & -9.02 & 0.54 & 0.52 \\
\hline PW & 30.20 & 31.55 & +4.47 & 0.25 & 0.99 \\
\hline BE & 10.08 & 14.60 & +44.84 & 1.09 & 0.38 \\
\hline Mean $\pm S E$ & $27.15 \pm 7.44$ & $33.71 \pm 8.22$ & & $0.58 \pm 0.08$ & $0.53 \pm 0.09$ \\
\hline
\end{tabular}




\section{References}

1. Dell'Osso LF. Congenital nystagmus: basic aspects. In: Lennerstrand G, Zee DS, Keller EL, eds. Functional Basis of Ocular Motility Disorders: Wenner-Gren Symposium Series. Oxford: Pergamon Press; 1982:129-138.

2. Dell'Osso LF, Daroff RB. Congenital nystagmus waveforms and foveation strategy. Doc Ophthalmol. 1975;39:155-182.

3. Dell'Osso LF, Troost BT. The ocular motor system: normal and clinical studies. In: Brooks BA, Bajandas FJ, eds. Eye Movements: New York: Plenum Press; 1976:41-63.

4. Van Vliet AGM. Nystagmus. Doc Ophthalmol. 1982;52:435-446.

5. Abadi RV, Whittle J. The nature of head postures in congenital nystagmus. Arch Ophthalmol. 1991;109:216-220.

6. Von Noorden GK, La Roche R. Visual acuity and motor characteristics in congenital nystagmus. Am J Ophthalmol. 1983;95:748751.

7. Abadi RV, Dickinson CM. Waveform characteristics in congenital nystagmus. Doc Ophthalmol. 1986;64:153-167.

8. Dell'Osso LF, Flynn JT, Daroff RB. Hereditary congenital nystagmus: an intrafamilial study. Arch Ophthalmol. 1974;92:366374 .

9. Tkalcevic LA, Abel LA. The effects of increased visual task demand on foveation in congenital nystagmus. Vision Res. 2005;45:11391146.

10. Abadi RV, Bjerre A. Motor and sensory characteristics of infantile nystagmus. Br J Ophthalmol. 2002;86:1152-1160.

11. Chung ST, Bedell HE. Velocity criteria for "foveation periods" determined from image motions simulating congenital nystagmus. Optom Vis Sci. 1996;73:92-103.

12. Dell'Osso LF, Jacobs JB. An expanded nystagmus acuity function: intra- and intersubject prediction of best-corrected visual acuity. Doc Ophthalmol. 2002;104:249-276.

13. Bedell HE, White JM, Abplanalp PL. Variability of foveations in congenital nystagmus. Clin Vision Sci. 1989;4:247-252.

14. Bifulco P, Cesarelli M, Loffredo L, Sansone M, Bracale M. Eye movement baseline oscillation and variability of eye position during foveation in congenital nystagmus. Doc Ophthalmol. 2003; 107:131-136.

15. Cesarelli M, Bifulco P, Loffredo L, Bracale M. Relationship between visual acuity and eye position variability during foveations in congenital nystagmus. Doc Ophthalmol. 2000;101:59-72.

16. Sheth NV, Dell'Osso LF, Leigh RJ, Van Doren CL, Peckham HP. The effects of afferent stimulation on congenital nystagmus foveation periods. Vision Res. 1995;35:2371-2382.

17. Shallo-Hoffmann J, Faldon M, Tusa RJ. The incidence and waveform characteristics of periodic alternating nystagmus in congenital nystagmus. Invest Ophthalmol Vis Sci. 1999;40:2546-2553.
18. Reulen JP, Marcus JT, Koops D, et al. Precise recording of eye movement: the IRIS technique. Part 1. Med Biol Eng Comput. 1988;26:20-26.

19. Garcia-Perez MA. Forced-choice staircases with fixed step sizes: asymptotic and small-sample properties. Vision Res. 1998;38: 1861-1881.

20. Ukwade MT, Bedell HE. Variation of congenital nystagmus with viewing distance. Optom Vis Sci. 1992;69:976-985.

21. Scheiman M, Wick B. Clinical Management of Binocular Vision: Heterophoric, Accommodative and Eye Movement Disorders. Philadelphia: Lippincott Williams \& Wilkins; 2002.

22. Everly GS, Rosenfeld R. The Nature and Treatment of the Stress Response: A Practical Guide for Clinicians. New York: Plenum Press; 1981.

23. Harris CM. Problems in modeling congenital nystagmus: towards a new model. In: Findlay, JM, Walker, R, Kentridge, RW, eds. Eye Movement Research: Mechanisms, Processes and Applications. Amsterdam: Elsevier; 1995:239-253.

24. Jacobs JB, Dell'Osso LF. Congenital nystagmus: hypotheses for its genesis and complex waveforms within a behavioral ocular motor system model. J Vis. 2004;4:604-625.

25. Hertle RW, Dell'Osso LF, FitzGibbon EJ, et al. Horizontal rectus tenotomy in patients with congenital nystagmus: results in 10 adults. Ophthalmology. 2003;110:2097-2105.

26. Dell'Osso LF. Development of new treatments for congenital nystagmus. Ann NY Acad Sci. 2002;956:361-379.

27. Wasicky R, Horn AK, Büttner-Ennever JA. Twitch and nontwitch motoneuron subgroups in the oculomotor nucleus of monkeys receive different afferent projections. J Comp Neurol. 2004;479: 117-129.

28. Eberhorn AC, Horn AK, Fischer P, Büttner-Ennever JA. Proprioception and palisade endings in extraocular eye muscles. Ann $N Y$ Acad Sci. 2005;1039:1-8.

29. Büttner-Ennever JA, Cohen B, Horn AK, Reisine H. Efferent pathways of the nucleus of the optic tract in monkey and their role in eye movements. J Comp Neurol. 1996;373:90-107.

30. Büttner-Ennever JA, Cohen B, Horn AK, Reisine H. Pretectal projections to the oculomotor complex of the monkey and their role in eye movements. J Comp Neurol. 1996;366:348-359.

31. Yakushin SB, Reisine H, Büttner-Ennever J, Raphan T, Cohen B. Functions of the nucleus of the optic tract (NOT). I. Adaptation of the gain of the horizontal vestibulo-ocular reflex. Exp Brain Res. 2000; 131:416- 432 .

32. Harris C, Berry D. A developmental model of infantile nystagmus. Semin Ophthalmol. 2006;21:63-69.

33. Harris CM, Berry D. A distal model of congenital nystagmus as non-linear adaptive oscillations. Nonlinear Dyn. 2006;44: $1-4$. 